\title{
Somaclonal variation in Asparagus officinalis plants regenerated by organogenesis from long-term callus cultures*
}

\author{
Ana Clara Pontaroli ${ }^{1}$ and Elsa Lucila Camadro ${ }^{2}$ \\ ${ }^{1}$ Instituto Nacional de Tecnología Agropecuaria, Estación Experimental Agropecuaria, \\ Laboratorio de Genética, Balcarce, Buenos Aires, Argentina. \\ ${ }^{2}$ Universidad Nacional de Mar del Plata, Facultad de Ciencias Agrarias, Balcarce, \\ Buenos Aires, Argentina.
}

\begin{abstract}
Somaclonal variation in plants regenerated by organogenesis from long-term cultured calluses of two diploid staminate genotypes of Asparagus officinalis cv. Argenteuil was characterized by plant phenotype, ploidy, meiotic behavior, pollen viability, fruit and seed set, and AFLP profiles. Phenotypic deviations from the donors were detected in foliage color, flower size, and cladode and flower morphology. Ploidy changes were observed in $37.8 \%$ of the 37 regenerants studied. Meiotic alterations in 12 out of 21 regenerants included laggards, dicentric bridges, micronuclei, restitution nuclei and polyads. Of the 408 AFLP markers screened in 43 regenerants and the donors, $2.94 \%$ showed polymorphism. High pollen viability was observed in the 22 regenerants analyzed. All crosses between one pistillate plant and 35 regenerants, as well as the controls, produced fruits and seeds; however, no plump seeds resulted in $35.3 \%$ of the crosses with regenerants, and no seeds germinated in $12.5 \%$ of those with apparently normal seeds. Fruit and seed set was similar in crosses with diploid regenerants with normal meiosis and the controls but was lower in crosses with diploid and polyploid regenerants with abnormal meiosis. Our results show that the regenerated plants exhibited conspicuous somaclonal variation that could be eventually exploited for in vitro selection systems.
\end{abstract}

Key words: AFLP, fertility, plant morphology, meiotic behavior, ploidy.

Received: October 14, 2004; Accepted: April 12, 2005.

\section{Introduction}

Garden asparagus (Asparagus officinalis L.) is a vegetable of high economic value. The main cause of asparagus crop decline in the world is the disease known as 'crown and root rot', caused by Fusarium spp. (Farr et al., 1989). Recovery of resistant asparagus cultivars through conventional breeding is hindered because Fusarium is ubiquitous in the soil, asparagus is perennial and dioecious, and disease resistance is subject to polygenic control (Lassaga et al., 1998). The application of in vitro selection techniques has facilitated the generation of disease resistant plants in other pathosystems (Crinò, 1997; Remotti, 1998). Many of these techniques exploit somaclonal variation that can arise or be detected during in vitro culture (Larkin and Scowcroft, 1981). However, before applying in vitro selection it is essential to identify the conditions which favor somaclonal variation and also to characterize such variation.

Send correspondence to Elsa L. Camadro. C.C. 276, (7620) Balcarce, Buenos Aires, Argentina. E-mail: ecamadro@balcarce.inta. gov.ar. 'Current address: Department of Genetics, University of Georgia, 30602 Athens, Georgia, USA. *Part of the first author's Doctoral Thesis.
Somaclonal variation in asparagus has mainly been investigated as an undesired phenomenon that may arise during mass propagation. For example, Kunitake et al. (1998) studied ploidy level and morphological variations while Raimondi et al. (2001) used a similar approach along with meiotic analysis and random amplified polymorphic DNA (RAPD) profiling to characterize somaclonal variation in plants regenerated by somatic embryogenesis. Both studies reported a low frequency of somaclones, presumably due to the mode of plant regeneration used, since embryogenesis is thought to involve stringent internal controls that may cause selection pressure against genetic changes (Swedlund and Vasil, 1985). In this sense, it has been suggested that organogenesis would favor the occurrence of somaclonal variation (Duncan, 1997).

In our laboratory we have developed an in vitro system consisting of long-term asparagus callus culture and plant regeneration through organogenesis to use in selection programs. The aim of the present study was to use asparagus phenotype, ploidy and fertility levels, meiotic behavior, and amplified fragment length polymorphism (AFLP) profiles of asparagus plants regenerated through 
this protocol to induce and characterize somaclonal variation that could be potentially selectable in vitro.

\section{Materials and Methods}

\section{Plant material}

The explant tissue culture donors were two staminate clones (genotypes) of Asparagus officinalis L. cultivar (cv) Argenteuil, identified as clone numbers 265 and 357, that had been selected in a local breeding program for yield and spear tip compactness under high temperature conditions at harvest. Pistillate plants of a diploid population were used in crosses with clones 265 and 357 and their regenerants; pollen from staminate plants of the population was pooled and used in control crosses with the same pistillate plants.

\section{In vitro culture}

Spear sections about $2 \mathrm{~mm}$ long and devoid of lateral buds were excised from micropropagated 265 and 357 plants which were more than a year old and placed in tubes containing $7 \mathrm{~mL}$ of callus growth medium (CGM), consisting of Murashige and Skoog's (1962) callus growth basal medium (MS medium) supplemented with $30 \mathrm{gL}^{-1}$ sucrose, $9 \mathrm{gL}^{-1}$ agar, $4.65 \mu \mathrm{M}$ kinetin and $6.79 \mu \mathrm{M}$ of 2,4-dichlorophenoxyacetic acid $(2,4-\mathrm{D})$. Cultures were kept in the dark at $26{ }^{\circ} \mathrm{C}$ and subcultured every 45 days. After nineteen months the callus sections were placed in tubes containing $7 \mathrm{~mL}$ of shoot primordia induction-shoot regeneration medium (SRM) consisting of MS salts supplemented with $5 \mathrm{mgL}^{-1}$ of 2 -isopentenyladenine (2iP), $1 \mathrm{mgL}^{-1}$ indolacetic acid (IAA), $30 \mathrm{gL}^{-1}$ sucrose and $5 \mathrm{gL}^{-1}$ agar. After 90 days of culture in the dark at $26^{\circ} \mathrm{C}$, calluses with shoot primordia were cultivated for 90 days at $26^{\circ} \mathrm{C}$ and a 16-h photoperiod in tubes containing $7 \mathrm{~mL}$ of shoot and mini-crown growth medium (MCM) consisting of MS salts supplemented with $1 \mathrm{mgL}^{-1}$ each of thiamine, nicotinic acid, pyridoxin, calcium pantothenate and glycine, $100 \mathrm{mgL}^{-1}$ myoinositol, $0.01 \mathrm{mgL}^{-1}$ biotin, $0.2 \mathrm{mgL}^{-1}$ kinetin, $0.2 \mathrm{mgL}^{-1} \alpha$-naphthalenacetic acid (NAA), $0.1 \mathrm{mgL}^{-1}$ benzylaminopurine (BA), $0.1 \mathrm{mgL}^{-1}$ ancymidol, $30 \mathrm{gL}^{-1}$ sucrose and $7 \mathrm{gL}^{-1}$ agar. Developed shoots and minicrowns were transferred to tubes containing $7 \mathrm{~mL}$ of rooting medium (RM) consisting of MS salts supplemented with $0.04 \mathrm{mgL}^{-1}$ thiamine, $1.32 \mathrm{mgL}^{-1}$ ancymidol, $0.1 \mathrm{mgL}^{-1}$ kinetin, $0.1 \mathrm{mgL}^{-1} \mathrm{NAA}, 70 \mathrm{gL}^{-1}$ glucose and $8 \mathrm{gL}^{-1}$ agar. Donor clones 265 and 357 were also micropropagated from axillary buds using appropriate media (i.e. SRM, MCM and RM sequentially). Plants with healthy and well-developed roots were transplanted to a sterilized mixture of soil, peat moss and perlite $(3: 1: 0.5$, $\mathrm{v} / \mathrm{v} / \mathrm{v}$ ) and placed in a greenhouse at $26{ }^{\circ} \mathrm{C}$ under a $16-\mathrm{h}$ photoperiod.

\section{Plant phenotype}

Plant height, cladode length and shape, foliage color, and flower morphology and size were compared with those of the respective donor clones and recorded for 38 regenerants (35 from clone 265 and three from clone 357 ).

\section{Cytogenetic studies}

For chromosome counts, spear tips were excised from $3 \mathrm{~cm}$-long spears and processed by the method of Raimondi et al. (2001). Meiotic studies were carried out based on the methodology of Camadro (1992), with various flowers and stamens per flower being analyzed for each genotype.

\section{Pollen viability}

Pollen samples were collected and stored in gelatin capsules at $4{ }^{\circ} \mathrm{C}$ for the crossing work. An indirect estimation of viability was made shortly after collection by staining pollen from each sample with $2 \% \mathrm{w} / \mathrm{v}$ acetocarmine in 1:1 acid:glycerol solution (Marks, 1954) and using optical microscopy to determine the percentage of round, wellstained pollen in 200 pollen grains per sample.

\section{Crosses}

In two seasons, two pistillate plants of the diploid population grown in the field were pollinated with stored pollen. Thirteen flowers were pollinated per genotypic combination. Forty-eight hours after pollination, three of the 13 pollinated pistils were removed and fixed in formaldehyde/acetic acid solution (FAA, containing 8:1:1 (v/v/v) $70 \%$ ethanol: glacial acetic acid: $40 \%$ formaldehyde); the other 10 pollinated pistils were left in situ for fruit and seed set. Fixed pistils were processed in $8 \mathrm{~N} \mathrm{NaOH}$ for $4 \mathrm{~h}$ and thoroughly rinsed with tap water (Martin, 1958) before being mounted in a drop of glycerin on a glass slide for examination by ultraviolet (UV) microscopy. Pollen/pistil compatibility relations were determined for all genotypic combinations, i.e. two pistillate diploid plants pollinated by (a) the donor clones, (b) a 'pool' of pollen from the diploid population and (c) 35 regenerants. Ripened fruits were harvested and seeds recovered and stored at $4{ }^{\circ} \mathrm{C}$. Seeds were sown in 100-mm-diameter Petri dishes, in a growth chamber at $26^{\circ} \mathrm{C}$ under a 16 -h photoperiod and the percentage of germination recorded 15 days later.

\section{AFLP analysis}

The method of Dellaporta et al. (1983) was used to extract DNA from tissue samples of the regenerants (34 derived from clone 265 and nine from clone 357 ) and their respective donor clones. The AFLP analysis was performed according to the method of Reamon-Büttner et al. (1998) except that for each sample $500 \mathrm{ng}$ of DNA was digested for $3 \mathrm{~h}$ at $37{ }^{\circ} \mathrm{C}$ with $5 \mathrm{U}$ EcoRI and $5 \mathrm{U}$ MseI. Amplification reactions were carried out with several combinations of primers with three selective nucleotides; reactions with selected primer combinations (E7-M20, E8-M17, E9-M18, E10-M22, E11-M16 and E12-M16) were duplicated (Table 1$)$. Ten $\mu \mathrm{L}$ of tracking dye (98\% formamide, $10 \mathrm{mM}$ 
EDTA pH 8.0, xylene cyanol and bromophenol blue) were added to each PCR reaction. Amplicons were denatured at $94{ }^{\circ} \mathrm{C}$ for $5 \mathrm{~min}$ and separated using $0.35 \mathrm{~mm}$-thick $5 \%$ vertical polyacrylamide gel electrophoresis, the gels being run using $1 \mathrm{X}$ TBE at a constant $50^{\circ} \mathrm{C}$ and $55-60 \mathrm{~W}$ for approximately $2 \mathrm{~h}$ and stained with silver nitrate (Silver Sequence Staining Reagents; Promega). Permanent positive images of the gels were made using automatic processor compatible APC Film (Promega) and the images scored visually, with intense bands only being included in the analysis.

\section{Results}

\section{Plant phenotype}

Foliage color was green for all the regenerants except one derived from clone 357, which was greenish blue (glaucous) (Table 2). Aberrant flowers with a higher than normal number of stamens (some of which were adhered to the tepals, some tepals also being fused with the terminal cladodes) occurred in two diploid, one triploid and two tetraploid regenerants derived from clone 265. Flower size was much larger in the tetraploid regenerants as compared with the other regenerants and the donor clones.

\section{Cytogenetic studies}

Both donor clones and 23 out of 37 of the regenerants were diploid $(2 n=2 x=20)$, although one mixoploid (20-30 chromosomes), four triploid and nine tetraploid regenerants also occurred (37.8\%). Although floral buds were fixed from 38 regenerants and the donor clones (Table 2), many of them were not at an appropriate stage to study. Consequently, meiosis was studied in the donor

Table 1 - Primers tested in the amplified fragment length polymorphism (AFLP) analysis of clones 265 and 357 and their respective regenerants.

\begin{tabular}{|c|c|}
\hline Denomination $^{\mathrm{a}}$ & Sequence \\
\hline E7 & 5' GACTGCGTACCAATTCAAA 3' \\
\hline E8 & 5' GACTGCGTACCAATTCAAC 3' \\
\hline E9 & 5' GACTGCGTACCAATTCAAG 3' \\
\hline E10 & 5' GACTGCGTACCAATTCACC 3' \\
\hline E11 & 5' GACTGCGTACCAATTCAGA 3' \\
\hline E12 & 5' GACTGCGTACCAATTCAGG 3' \\
\hline E13 & 5' GACTGCGTACCAATTCATC 3' \\
\hline E14 & 5' GACTGCGTACCAATTCATT 3' \\
\hline M15 & 5' GATGAGTCCTGAGTAACAA 3 \\
\hline M16 & 5' GATGAGTCCTGAGTAACAT 3' \\
\hline M17 & 5' GATGAGTCCTGAGTAACCA 3' \\
\hline M18 & 5' GATGAGTCCTGAGTAACCG 3' \\
\hline M19 & 5' GATGAGTCCTGAGTAACCT 3' \\
\hline M20 & 5' GATGAGTCCTGAGTAACGC 3' \\
\hline M22 & 5' GATGAGTCCTGAGTAACTC 3' \\
\hline
\end{tabular}

${ }^{\mathrm{a}} \mathrm{E}=E c o \mathrm{RI}+3$ primer; $\mathrm{M}=M s e \mathrm{I}+3$ primer clones and in 21 regenerants: 14 diploids, 13 from clone 265 and one from clone 357; two triploids from clone 265; and five tetraploids, four from clone 265 and one from clone 357. Meiosis was normal in both donor clones (not shown) and in nine out of the 14 diploid regenerants. The remaining regenerants exhibited several meiotic abnormalities (Table 2) such as laggards and dicentric bridges in meiosis I and/or II (Figure 1a) and bivalent migration in anaphase II and micronucleated sporads (2.9-38.1\%) were also observed (Figure 1b).

Lack of cytokinesis in meiosis II in one or both cells was observed in two regenerants, along with triads in regenerant 8 -I derived from callus 10 of clone 265 , and with dyads, triads and monads in regenerant 6-I derived from callus 64 of clone 265. In regenerant 2-I (derived from callus 46 of clone 265) chromatid segregation occurred after prophase II and meiosis ceased prematurely at this point in $64.5 \%$ of meiocytes, resulting in a high percentage $(52.7 \%)$ of dyads (Figure 1c). Another meiotic abnormality, i.e. sporads with five to seven microspores ('polyads'), was detected in seven regenerants (Table 2; Figure 1d). Microspores contained in these abnormal sporads were of heterogeneous size and frequently exhibited micronuclei.

\section{Pollen viability}

Pollen viability was $90 \%$ in both donor clones and oscillated between 60 and $90 \%$ in the regenerants (nine diploids, one triploid and four tetraploids; Table 2).

\section{Crosses}

All cross-pollinations were compatible, although fruit and seed set was low even when the pollinators were the donor clones or the plants from the population (control). This was attributed to the fact that the shoots of the pistillate plants were close to senescence, so these crosses were repeated in spring. All crosses set fruits and seeds; however, no plump seeds (an indication of seed viability) were obtained in $35 \%$ of crosses involving regenerants, and no seeds germinated in $12.5 \%$ of plants that produced apparently normal seeds (data not shown). Fruit and seed set was, on average, similar in control crosses and crosses with diploid regenerants with normal meiosis ( 5 to 6 fruits per plant, and 3-3.41 seeds/fruit) but it was lower in crosses with diploid regenerants with abnormal meiosis (3.4 fruits per plant, 2.5 seeds/fruit), and even lower in crosses with polyploid regenerants, all of which had abnormal meiosis (2.2 fruits per plant, 2.2 seeds/fruit) (Table 3 ). The percentage of seed germination followed a similar tendency, except that (as compared to the controls) it was also reduced in the crosses with diploid regenerants with normal meiosis (Table 3).

\section{AFLP analysis}

Our AFLP analysis of the donor clones and 43 regenerants (34 derived from clone 265 and nine from 
Table 2 - Phenotypic deviation from the donor clone, ploidy, meiotic behavior and pollen staining in regenerants derived from clones 265 and 357.

\begin{tabular}{|c|c|c|c|c|c|c|c|c|c|}
\hline \multirow{3}{*}{$\begin{array}{l}\text { Donor } \\
\text { clone }\end{array}$} & \multirow{3}{*}{$\begin{array}{c}\text { Callus } \\
\text { N. }\end{array}$} & \multirow[t]{3}{*}{ Regenerant } & \multirow[t]{3}{*}{$\mathrm{PD}^{\mathrm{a}}$} & \multirow{3}{*}{$\begin{array}{l}\text { Ploidy } \\
\text { (2n) }\end{array}$} & \multicolumn{4}{|c|}{ Meiotic behavior } & \multirow{3}{*}{$\begin{array}{l}\text { Stained } \\
\text { pollen } \\
(\%)\end{array}$} \\
\hline & & & & & \multirow[t]{2}{*}{ Type } & \multirow[t]{2}{*}{ Stage } & \multicolumn{2}{|l|}{ Abnormalities } & \\
\hline & & & & & & & Type and \% meiocytes ${ }^{\mathrm{b}}$ & $\mathrm{N}^{\mathrm{c}}$ & \\
\hline \multirow[t]{37}{*}{265} & 04 & $1-\mathrm{I}$ & none & $2 x=20$ & normal $^{\mathrm{d}}$ & & & & $-\mathrm{e}$ \\
\hline & & $8-\mathrm{C}$ & none & $3 x=30$ & abnormal & meiosis I & $1(46.6) ; 2(11.4)$ & 88 & - \\
\hline & & & & & & meiosis II & $1(70.4) ; 2(18.5)$ & 27 & \\
\hline & & & & & & sporad & $3(38.1) ; 4(8.8) ; 5(19.5)$ & 113 & \\
\hline & 05 & $2-\mathrm{C}$ & none & $2 x=20$ & normal & & & & $\approx 70$ \\
\hline & 10 & $7-\mathrm{C}$ & none & $3 x=30$ & - & & & & - \\
\hline & & $5-\mathrm{I}$ & none & $20-30$ & - & & & & - \\
\hline & & $8-\mathrm{I}$ & 1 & $4 x=40$ & abnormal & sporad & $3(38) ; 4(4.8) ; 5$ (26.4); 6 (2.9); 7 (6.3) & 208 & $>90$ \\
\hline & 18 & $5-\mathrm{C}$ & none & $2 x=20$ & abnormal & sporad & $3(7.4)$ & 136 & $\approx 90$ \\
\hline & & $8-\mathrm{C}$ & 1 & $4 x=40$ & - & & & & $>90$ \\
\hline & 25 & 7-I & none & $2 x=20$ & - & & & & $\approx 60$ \\
\hline & 26 & $5-\mathrm{I}$ & none & $2 x=20$ & normal & & & & $>90$ \\
\hline & & $7-\mathrm{I}$ & none & $2 x=20$ & abnormal & meiosis I & 1 and $2(\%$ not determined $)$ & 50 & $\approx 80$ \\
\hline & 35 & $5-\mathrm{C}$ & none & $3 x=30$ & - & & & & $\approx 70$ \\
\hline & & $1-\mathrm{C}$ & 1 & $4 x=40$ & - & & & & $>90$ \\
\hline & 45 & $3-\mathrm{C}$ & none & $2 x=20$ & normal & & & & - \\
\hline & & $5-\mathrm{C}$ & none & $2 x=20$ & - & & & & - \\
\hline & & $5-\mathrm{I}$ & none & $2 x=20$ & normal & & & & $>90$ \\
\hline & 46 & $1-\mathrm{C}$ & 2 & $2 x=20$ & abnormal & sporad & $3,4,5,6$ and 8 (\% not determined $)$ & 50 & $>90$ \\
\hline & & $2-\mathrm{C}$ & none & $2 x=20$ & abnormal & meiosis II & $1(5)$ & 152 & $>90$ \\
\hline & & $6-\mathrm{C}$ & none & $2 x=20$ & normal & & & & $>90$ \\
\hline & & $8-\mathrm{C}$ & 1 & $4 x=40$ & - & & & & - \\
\hline & & $2-\mathrm{I}$ & 1 & $4 x=40$ & abnormal & $\begin{array}{l}\text { meiosis I } \\
\text { meiosis II } \\
\text { sporad }\end{array}$ & $\begin{array}{c}1(50) ; 2(5) \\
1(7.5) ; 2(1) ; 9(6.5) ; 10(64.5) \\
3(20) ; 4(3.4) ; 5(10.7) ; 8(52.7)\end{array}$ & $\begin{array}{r}20 \\
93 \\
205\end{array}$ & - \\
\hline & & $5-\mathrm{I}$ & none & $2 x=20$ & abnormal & meiosis II & 1 and $2(\%$ not determined $)$ & 50 & - \\
\hline & 47 & $8-\mathrm{C}$ & 2 & $3 x=30$ & abnormal & sporad & $4(6)$ & 150 & - \\
\hline & & 7-I & 1 & - & - & & & & - \\
\hline & 55 & $2-\mathrm{I}$ & none & $2 x=20$ & normal & & & & $>90$ \\
\hline & 56 & $2-C$ & none & $2 x=20$ & normal & & & & $>90$ \\
\hline & & $4-C$ & none & $2 x=20$ & - & & & & - \\
\hline & & $5-C$ & none & $2 x=20$ & - & & & & - \\
\hline & & $6-C$ & none & $2 x=20$ & - & & & & - \\
\hline & & $6-\mathrm{I}$ & none & $2 x=20$ & - & & & & $>90$ \\
\hline & & 8 -I & none & $2 x=20$ & - & & & & $>90$ \\
\hline & 64 & $4-\mathrm{I}$ & 1 & $4 x=40$ & - & & & & $\approx 70$ \\
\hline & & $6-\mathrm{I}$ & $1,2,3$ & $4 x=40$ & abnormal & $\begin{array}{l}\text { meiosis I } \\
\text { meiosis II } \\
\text { sporad }\end{array}$ & $\begin{array}{c}1(44.6) \\
1(29.8) ; 7(24.5) \\
3(2.9) ; 5(2) ; 6(3.9) ; 8(31.4) ; 11(2)\end{array}$ & $\begin{array}{r}56 \\
57 \\
102\end{array}$ & - \\
\hline & 66 & 7-C & 2 & $2 x=20$ & - & & & & - \\
\hline & & 8-I & $1,2,3$ & $4 x=40$ & abnormal & sporad & $3(12.7) ; 4(6.1) ; 5(24.6)$ & 212 & - \\
\hline \multirow[t]{3}{*}{357} & 11 & $3-\mathrm{C}$ & 1,4 & $4 x=40$ & abnormal & sporad & 3 (12.9); 4 (5.7); 5 (19.2) & 209 & - \\
\hline & 17 & $6-\mathrm{I}$ & none & $2 x=20$ & normal & & & & $>90$ \\
\hline & & 7-I & none & $2 x=20$ & - & & & & $>90$ \\
\hline
\end{tabular}

${ }^{\mathrm{a}} \mathrm{PD}=$ Phenotypic deviations from the donor clone: 1 = larger flower; 2 = aberrant flowers; 3 = aberrant cladodes; $4=$ glaucous foliage. ${ }^{\mathrm{b}}$ Meiotic abnormalities (with \% of abnormal meiocytes between parenthesis): $1=$ laggards; $2=$ dicentric bridges; $3=$ micronuclei; $4=$ polyads; $5=$ polyads and micronuclei in the same meiocyte; $6=$ triads; $7=$ chromosome segregation without further cytokinesis II (in one or both cells); $8=$ dyads; $9=$ bivalent migration in anaphase II; $10=$ chromatid separation after prophase II and premature end of meiosis; $11=$ monads. ${ }^{\mathrm{c}} \mathrm{N}=$ number of meiocytes analyzed. ${ }^{\mathrm{d}}$ At least 100 meiocytes analyzed in each meiotic stage. ${ }^{\text {e }}$ Sample not analyzed. 
clone 357) resulted in a total of 408 amplified fragments; the number of fragments per plant and primer combination varied from 61 to 84 with an average of 68 . All plants analyzed shared 279 fragments $(68.38 \%)$, while another 117 fragments $(28.68 \%)$ were polymorphic between donor clones. Clone 265 and its derived regenerants shared 51 fragments that were absent in the other plants, while 66 fragments appeared exclusively in clone 357 and its derived regenerants. The remaining 12 fragments $(2.94 \%)$ showed variability between eight of the regenerants (six de-
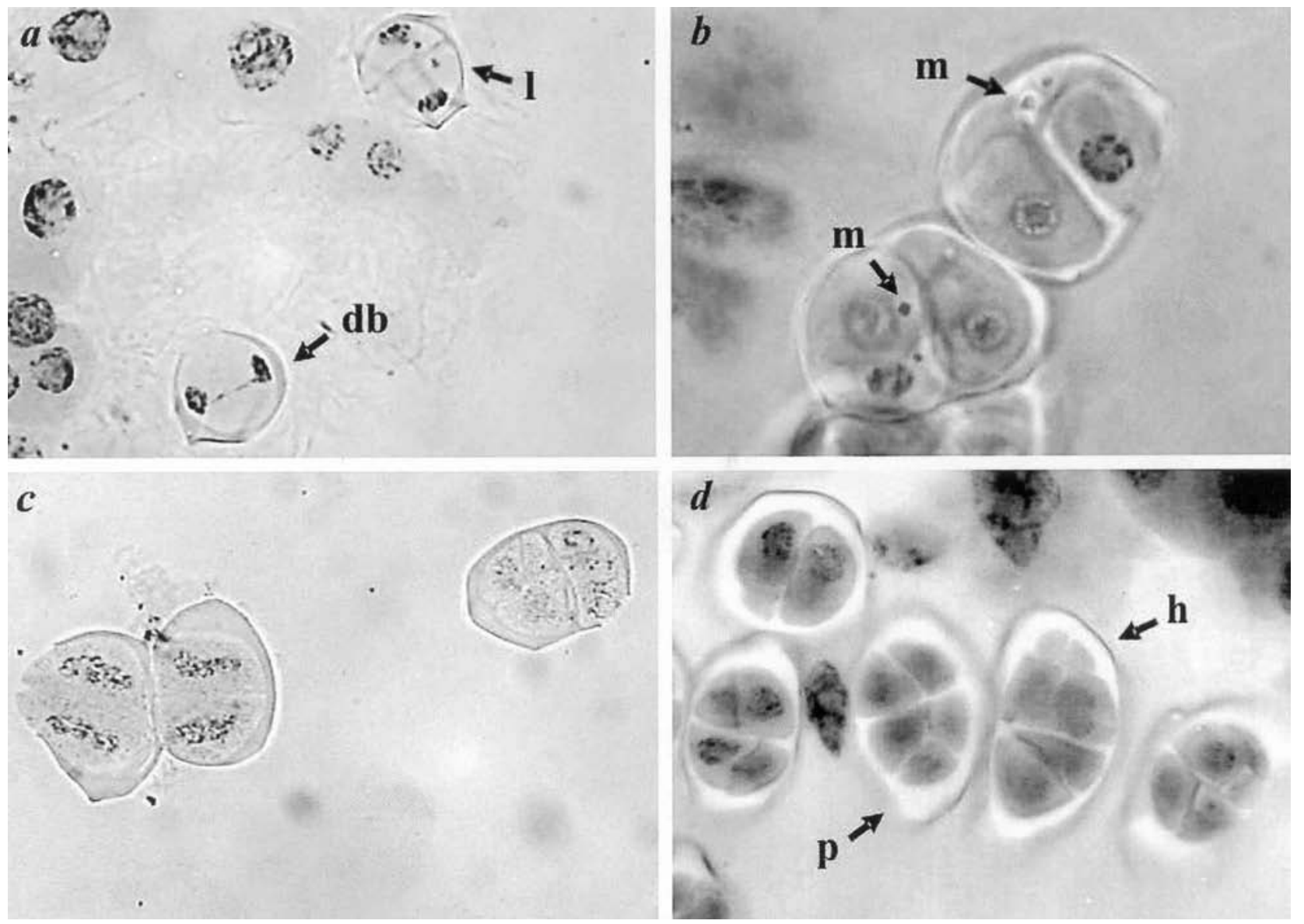

Figure 1 - Meiotic abnormalities of regenerants derived from calluses of clones 265 and 357. (a) Regenerant 5-I derived from callus 46 of clone 265, laggard (1) in cytokinesis I and dicentric bridge (db) in telophase I. (b) Regenerant 3-C derived from callus 11 of clone 357, sporads with micronuclei (m). (c) Regenerant 2-I derived from callus 46 of clone 265 , two sporads with chromatid segregation in prophase II and premature end of meiosis (left) and normal tetrad (right). (d) Regenerant 8-I derived from callus 66 of clone 265, pentad (p) and hexad (h).

Table 3 - Fruit, seed set and percentage seed germination for clones 265 and 357 and their derived regenerants classified according to ploidy and meiotic behavior.

\begin{tabular}{|c|c|c|c|c|c|c|c|c|c|}
\hline Genotype & Meiotic behavior & $N .^{a}$ & N. fruits ${ }^{1}$ & N. seeds ${ }^{2}$ & N. seeds/fruit & $\begin{array}{l}\text { N. plump } \\
\text { seeds }^{3}\end{array}$ & $\begin{array}{l}\text { N. plump } \\
\text { seeds/fruit }\end{array}$ & $\begin{array}{l}\text { N. germinated } \\
\text { seeds }\end{array}$ & $\% \mathrm{G}^{\mathrm{b}}$ \\
\hline '265' & normal & 1 & 6 & 19 & 3.17 & 14 & 2.33 & 10 & 71.4 \\
\hline ' 357 ' & normal & 1 & 5 & 15 & 3 & 11 & 2.2 & 8 & 72.7 \\
\hline \multirow[t]{2}{*}{$2 \mathrm{x}$ regenerants } & normal & 8 & $\begin{array}{c}5.125 \\
(4,4,8,4,9,5 \\
2,5)\end{array}$ & $\begin{array}{c}17.5 \\
(16,15,25,12 \\
37,17,5,13)\end{array}$ & 3.41 & $\begin{array}{c}10.25 \\
(10,13,14,6 \\
14,12,5,8)\end{array}$ & 2 & $\begin{array}{c}5.375 \\
(2,9,5,4,8,8 \\
2,5)\end{array}$ & 52.44 \\
\hline & abnormal & 5 & $\begin{array}{c}3.4 \\
(3,6,3,3,2)\end{array}$ & $\begin{array}{c}8.4 \\
(7,14,14,5,2)\end{array}$ & 2.47 & $\begin{array}{c}5.8 \\
(7,9,11,2,0)\end{array}$ & 1.7 & $\begin{array}{c}2.4 \\
(7,0,5,0,0)\end{array}$ & 41.38 \\
\hline $\begin{array}{l}3 x \text { and } 4 x \\
\text { regenerants }\end{array}$ & abnormal & 6 & $\begin{array}{c}2.17 \\
(3,2,1,2,3,2)\end{array}$ & $\begin{array}{c}4.83 \\
(5,8,4,1,6,5)\end{array}$ & 2.23 & $\begin{array}{c}0.5 \\
(1,0,0,0,1,1)\end{array}$ & 0.23 & $\begin{array}{c}0.17 \\
(1,0,0,0,0,0)\end{array}$ & 34 \\
\hline
\end{tabular}

${ }^{a}$ Number of genotypic combinations. ${ }^{1,2,3,4}$ Average; between parenthesis are the values of each genotypic combination. ${ }^{{ }^{b}} \% \mathrm{G}=\%$ seed germination, based of the number of plump seeds. 
rived from clone 265 and two from clone 357) and their respective donor clones (Table 4). None of these polymorphisms was shared by regenerants derived from different donor clones. Only two regenerants derived from the same callus (regenerants 6-I and 7-I, derived from callus 17 of clone 357) exhibited the same polymorphism in comparison with the donor clone (Table 4).

\section{Discussion}

Our results reveal conspicuous somaclonal variation in asparagus plants regenerated by organogenesis from long-term callus cultures. Phenotypic variants included aberrant flowers and cladodes, larger flower size and glaucous foliage. Flower abnormalities were similar to those found by Chang and Hung (1982) in terminal flowers of cv. UC 309 but in our case they occurred in all the flowers of a plant, indicating that they could be the result of mutations or modifications in the expression of the gene(s) involved in flower development. The increase in flower size in all tetraploid regenerants with respect to the donor clones and the rest of regenerants was probably due to the higher ploidy level, as has been widely observed in other species and organs (Blakeslee, 1941). The phenomenon of ploidy variation in plants regenerated from callus, observed in the present work, has previously been reported in asparagus (Kunitake et al., 1998; Raimondi et al., 2001) and other species (Larkin and Scowcroft, 1981; Singh, 1993; Duncan, 1997; Gupta, 1998). The proportion of regenerants that differed in chromosome number from the respective donor plant $(37.8 \%)$ is much higher than that reported in similar studies (Larkin and Scowcroft, 1981; Singh, 1993; Duncan, 1997; Gupta, 1998), which could be ascribed to the fact that we used older calluses and longer subculture intervals in order to maximize somaclonal variation. Alternatively or additionally, it is feasible that ploidy differences resided in the explant (preexistent variation), as polysomatic species such as asparagus can exhibit endoreduplication in certain cell types (Bhojwani and Razdan,
1996). This could be reinforced by the fact that the explants were obtained from a highly differentiated tissue composed of several cell types. In our study, the occurrence of conspicuous ploidy variation among regenerants contradicts the evidence that morphogenic calluses generally bear the same chromosome number as the donor genotype (Gupta, 1998) and the idea that plant regeneration constitutes a selective instance against the chromosome number deviations observed during the callus phase (Bhojwani and Razdan, 1996; Singh, 1993). However, in asparagus, this selection against ploidy variation among regenerants could take place in long-term (10-year-old) stabilized callus cultures as found by Reuther (1990).

The mode of plant regeneration can have a great influence on the level of somaclonal variation (Duncan, 1997). Kunitake et al. (1998) detected little ploidy and phenotypic variation among somaclones obtained through somatic embryogenesis from asparagus genotypes. Similar results were obtained by Raimondi et al. (2001) on research with the same two clones as those used in our study, finding only two plants that were phenotypically different from the donor clone, three with ploidy variation and abnormal meiosis, and a lack of intraclonal polymorphisms in the RAPD markers. The much lower proportion of somaclonal variants found by Raimondi et al. (2001) in relation to our study could be attributed to callus age, i.e. seven months in their study compared to 19 months in our study. However, it is also feasible that somatic embryogenesis operated as a selection mechanism against chromosome and gene alterations, as observed in other work with asparagus (Araki et al. 1992).

The laggards and dicentric bridges in meiosis I and II, bivalent migration in anaphase II and sporads with micronuclei observed in our study have frequently been found in somaclonal variation studies (Larkin and Scowcroft, 1981; Singh, 1993; Bhojwani and Razdan, 1996; Gupta, 1998). Chromosome mispairing, gross chromosome rearrangements, ruptures in heterochromatic regions and transposon

Table 4 - Amplified fragment length polymorphism (AFLP) markers polymorphic among regenerants and their respective donor clones (265 and 357 ).

\begin{tabular}{|c|c|c|c|c|}
\hline Donor clone & Callus & Regenerant & Polymorphism type & Markers ${ }^{\mathrm{a}}$ \\
\hline \multirow[t]{6}{*}{265} & 10 & 8-I & Absence & E10-M22-4, E10-M22-38, E9-M18-3, E9-M18-5, E9-M18-7, E9-M18-32, E9-M18-41 \\
\hline & & & Presence & E9-M18-6, E7-M20-13 \\
\hline & 18 & $5-\mathrm{C}$ & Absence & E10-M22-4, E10-M22-38, E9-M18-3, E9-M18-5, E9-M18-32 \\
\hline & 26 & 7-I & Absence & E10-M22-4, E10-M22-38, E9-M18-5, E9-M18-32 \\
\hline & 60 & 1-I & Absence & E9-M18-29 \\
\hline & 64 & 4-I & Absence & E9-M18-3, E9-M18-32 \\
\hline \multirow[t]{3}{*}{357} & 17 & 6-I & Presence & E10-M22-41 \\
\hline & & 7-I & Absence & E7-M16-18 \\
\hline & & & Presence & E10-M22-41 \\
\hline
\end{tabular}

${ }^{a}$ Markers are denominated with the primer combination used plus the order of the marker in the lane (the higher the number the lower the molecular weight). 
activation, among other phenomena, have been related to these abnormalities (Peschke and Phillips, 1992; Kaeppler et al., 1998; Cassells and Curry, 2001, among others). Some authors have suggested that the above phenomena could derive from a direct or indirect effect of 2,4-D (given its mutagenic character), oxidative stress, changes in methylation patterns, and/or a combination of these and other factors. This could be the case in the present work, as 2,4-D and a long-term culture period were used in the callus stage.

The other meiotic abnormality found in the regenerants was the production of microspores with unreduced chromosome numbers and while meiosis was normal in both donor clones, dyads, triads and/or monads were observed in four regenerants derived from '265' (one diploid and three tetraploids) derived from clone 265. Camadro (1992) observed similar variants in A. officinalis, $A$. densiflorus and $A$. plumosus, and hypothesized that the tendency towards these types of meiotic abnormalities is under genetic control as it is in potato and alfalfa. In our study, microspores with unreduced chromosome number could have originated from a mutational phenomenon, transposon excision or insertion (as Chen et al. (2002) found in Arabidopsis) or modifications in the regulation of gene(s) involved in the meiotic process.

The formation of polyads that we detected in one diploid, two triploid and four tetraploid regenerants has not previously been reported for somaclones, although Caetano-Pereira and Pagliarini (2001) found a spontaneous maize mutant that produces similar polyads to those detected by us. Polyad formation has been also described in Solanum commersonii (+) S. tuberosum somatic hybrids (Conicella et al. 1997) and in two mutants of Arabidopsis thaliana, tam (Magnard et al. 2001) and atk1-1 (Chen et al. 2002), the atk1-1 polyads occurring as a result of defective spindles as a consequence of the insertion of a $D s$ element in the ATK-1 gene. The diploid regenerant (1-C, derived from callus 46 of clone 265) had a high percentage of viable pollen and fruit and seed set and a high percentage seed germination (45.5\%) similar to the controls; on the other hand, the remaining two triploid and four tetraploid regenerants had very low fruit and seed set and mostly empty seeds (data not shown). Pollen staining in the regenerant with the highest percentage of polyads (8-I, derived from callus 10 of clone 265) was $90 \%$, but when these regenerants were used in crosses some pollen grains were functional but almost all seeds were empty, indicating that in this material staining was inadequate for indirectly estimating pollen viability. Although the occurrence of meiotic abnormalities negatively affected fruit and seed set (Table 3) progenies were obtained from many crosses, and this constitutes a positive result in the context of a breeding program.

Although performed on a reduced scale, AFLP analysis revealed polymorphisms between regenerants and their respective donor clones. Although AFLP analysis is not as widely used in this type of study as RFLP or RAPD, Polanco and Ruiz (2002) used it to detected somaclonal variation in Arabidopsis and Vendrame et al. (1999) in pecan nuts. In asparagus, Raimondi et al. (2001) found no intraclonal polymorphisms for RAPD in 77 regenerants obtained by somatic embryogenesis from the same clones as were used in our study, but Raimondi et al. (2001) used a smaller number of markers (157 as against 408 in our study) and, analogously to what was previously discussed regarding ploidy variation, differences in callus age and/or mode of regeneration of somaclones could account for the differences in the results.

Six out of the 12 markers exhibiting intraclonal polymorphism were absent in two to four regenerants depending on the marker (Table 4). Only one of these regenerants derived from the same callus (regenerants 6-I and 7-I derived from callus 17 of clone 357), suggesting that both plants could have originated from a group of cells that shared that mutation. The remaining cases could be explained by independent mutations in the same sequences or, alternatively, a unique mutational event could have occurred in one of the several micropropagated plants that were used as explant sources. Since the origin of the explants was not documented, it was not possible to ascertain whether or not the calluses from which these regenerants were derived were induced from adjacent explants or explants excised from the same spear.

It is also important to consider the results obtained using the different approaches for characterizing somaclonal variation as related to the callus from which each regenerant was obtained. Thirteen out of the sixteen calluses yielded more than one regenerant but in only two of these (calluses 45 and 56 of clone 265) were all regenerants diploid, had similar morphology and fruit and seed set as the donor clone and exhibited normal chromosome behavior. The regenerants obtained from the remaining $11 \mathrm{cal}-$ luses showed variations in one to all of the factors analyzed (plant phenotype, ploidy, meiotic behavior, reproductive parameters and AFLP profile) as compared with other regenerants derived from the same callus. It is particularly important to consider this variation when regenerating plants from callus after in vitro screening for a certain trait because, according to our results, many calluses seem to exhibit a heterogeneous (epi)genetic and/or chromosomal constitution after long-term culture that can eventually be manifested in the regenerants.

The different approaches used by us in this study appear to be reliable and complementary tools for assessing somaclonal variation in asparagus. The conspicuous variability detected appears to be exploitable for in vitro selection programs.

\section{Acknowledgments}

This study was partially financed by the Consejo Nacional de Investigaciones Científicas y Técnicas 
(CONICET) and the Universidad Nacional de Mar del Plata (UNMdP).

\section{References}

Araki H, Shimazaki H, Hirata Y, Oridate T, Harada T and Yakuwa $\mathrm{T}$ (1992) Chromosome number variation of callus cells and regenerated plants in Asparagus officinalis L. Plant Tis Cult Lett 9:169-175.

Bhojwani SS and Razdan MK (1996) Plant Tissue Culture: Theory and Practice, a Revised Edition. Elsevier, Amsterdam, Lausanne, New York, Oxford, Shannon, Tokyo, 767 pp.

Blakeslee AF (1941) Effect of induced polyploidy in plants. Amer Nat 117-135.

Caetano-Pereira CM and Pagliarini MS (2001) A new meiotic abnormality in Zea mays: Multiple spindles associated with abnormal cytokinesis in both divisions. Genome 44:865871.

Camadro EL (1992) Cytological mechanism of 2n microspore formation in garden asparagus. HortScience 27:831-832.

Cassells AC and Curry RF (2001) Oxidative stress and physiological, epigenetic and genetic variability in plant tissue culture: Implications for micropropagators and genetic engineers. Plant Cell Tis Org Cult 64:145-157.

Chang TL and Hung L (1982) The tip-flower character of asparagus (Asparagus officinalis L.) I. The morphology and incidence of tip-flower of older seedlings. Mem Coll Agric, Natl Taiwan Univ 22:95-101.

Chen C, Marcus A, Li W, Hu Y, Vielle Calzada JP, Grossniklaus U, Cyr RJ and Ma H (2002) The Arabidopsis ATK1 gene is required for spindle morphogenesis in male meiosis. Development 129:2401-2409.

Conicella C, Genualdo G, Lucia R, Ramulu KS and Cardi T (1997) Early tapetal degeneration and meiotic defects are involved in the male sterility of Solanum commersonii $(+) S$. tuberosum somatic hybrids. Theor Appl Genet 95:609-617.

Crinò P (1997) Culture filtrate as selective agent of resistance to phytopathogenic fungi. In: Upadhyay RK and Mukerji KG (eds) Toxins in plant disease development and evolving biotechnology. Science Publishers, Inc., USA, pp 183-208.

Dellaporta SL, Wood J and Hicks JB (1983) A plant DNA minipreparation: Version II. Plant Mol Biol Rep 1:19-21.

Duncan RR (1997) Tissue culture-induced variation and crop improvement. Adv Agron 58:201-240.

Farr DF, Bills GF, Chamuris GP and Rossman AY (1989) Fungi on Plants and Plant Products in the United States. APS Press - The American Phytopathological Society, St. Paul, Minnesota, $1252 \mathrm{pp}$.

Gupta PK (1998) Chromosomal basis of somaclonal variation in plants. In: Jain SM, Brar DS and Alhoowalia BS (eds) Somaclonal Variation and Induced Mutations in Crop Improvement. Kluwer Academic Publishers, Dordrecht, Boston, London, pp 149-168.

Kaeppler SM, Phillips RL and Olhoft P(1998) Molecular basis of heritable tissue culture-induced variation in plants. In: Jain
SM, Brar DS and Alhoowalia BS (eds) Somaclonal Variation and Induced Mutations in Crop Improvement. Kluwer Academic Publishers, Dordrecht, Boston, London, pp 465484.

Kunitake H, Nakashima T, Mori K and Tanaka M (1998) Somaclonal and chromosomal effects of genotype, ploidy and culture duration in Asparagus officinalis L. Euphytica 102:309-316.

Larkin PJ and Scowcroft WR (1981) Somaclonal variation - A novel source of variability from cell cultures for plant improvement. Theor Appl Genet 60:197-214.

Lassaga SL, Camadro EL and Babinec FJ (1998) Assessing genetic variability for Fusarium resistance in three asparagus populations with an in vitro assay. Euphytica 103:131-136.

Magnard JL, Yang M, Chen YCS, Leary M and McCormick S (2001) The Arabidopsis gene tardy asynchronous meiosis is required for the normal pace and synchrony of cell division during male meiosis. Plant Physiol 127:1157-1166.

Marks GE (1954) An acetocarmine glycerol jelly for use in pollen fertility counts. Stain Technol 29:277.

Martin FW (1958) Staining and observing pollen tubes in the style by means of fluorescence. Stain Technol 34:125-128.

Murashige T and Skoog F (1962) A revised medium for rapid growth and bioassays with tobacco tissues cultures. Physiol Plant 15:473-479.

Peschke VM and Phillips RL (1992) Genetic implications of somaclonal variation in plants. Adv Genet 30:41-75.

Polanco C and Ruiz ML (2002) AFLP analysis of somaclonal variation in Arabidopsis thaliana regenerated plants. Plant Sci 162:817-824.

Raimondi JP, Camadro EL and Masuelli RW (2001) Assessment of somaclonal variation in asparagus by RAPD fingerprinting and cytogenetic analyses. Sci Hortic 90:19-29.

Reamon-Büttner SM, Schondelmaier J. and Jung C (1998) AFLP markers tightly linked to the sex locus in Asparagus officinalis L. Mol Breed 4:91-98.

Remotti PC (1998) Somaclonal variation and in vitro selection for crop improvement. In: Jain SM, Brar DS and Alhoowalia BS (eds) Somaclonal Variation and Induced Mutations in Crop Improvement. Kluwer Academic Publishers, Dordrecht, Boston, London, pp 169-201.

Reuther G (1990) Histological and cytological selection of somaclonal and induced variants of asparagus derived from callus cultures. Acta Hortic 280:385-393.

Singh RJ (1993) Chromosomal aberrations in cell and tissue culture derived calluses and their regenerants. In: Singh RJ (ed) Plant Cytogenetics. CRC Press; Boca Raton, Ann Arbor, London, Tokyo, pp 285-307.

Swedlund B and Vasil IK (1985) Cytogenetic characteristics of embryogenic callus and regenerated plants of Pennisetum americanum (L) K Schum. Theor Appl Genet 69:575-581.

Vendrame WA, Kochert G and Wetzstein HY (1999) AFLP analysis of variation in pecan somatic embryos. Plant Cell Rep 18:853-857.

Associate Editor: Márcio de Castro Silva Filho 